\title{
O papel da Advocacia Geral da União na judicialização das políticas de saúde
}

The Union General Attorney (AGU) Office's role in the health policies judicialization

\section{Maria Angelica Borges dos Santos}

Médica, Doutora em Saúde Pública. Escola Nacional de Saúde Pública / Fundação Oswaldo Cruz. Rio de Janeiro, Brasil.

\section{Pedro Lambert Passos Bellagamba.}

Aluno da Faculdade de Direito. Pontifícia Universidade Católica do Rio de Janeiro, Brasil.

\section{Karinna de Freitas Borges.}

Aluna da Faculdade de Direito. Universidade Federal do Rio de Janeiro, Brasil.

Resumo: O foco dominante da pesquisa sobre judicialização em saúde no Brasil tem sido a ação dos tribunais na implementação de políticas para garantia do Direito à saúde. A judicialização da "política pura", onde se transferem para o âmbito jurídico questões de natureza claramente políticas, ainda é pouco estudada. Nesse sentido a Advocacia Geral da União (AGU) tem tido papel destacado. Método: Revisão de pareceres, normas, resoluções e informações de caráter consultivo relacionados à saúde no período entre 1993 e maio de 2013, identificadas no site da AGU. Seleção de três peças com temas de alto impacto potencial sobre a configuração do sistema de saúde brasileiro, sendo analisadas origem e tramitação da solicitação e argumentação que sustentou as conclusões finais. Resultado: Foram selecionados: um parecer que interpreta valores da contribuição federal para o financiamento do sistema público de saúde; uma informação sobre participação de capital estrangeiro em operadora de plano de saúde com rede própria de senviços de assistência à saúde, base para a aprovação da aquisição de empresa nacional por empresa estrangeira; e um parecer sobre competências da Agência Nacional de Vigilância Sanitária (ANVISA) e do Instituto de Nacional de Propriedade Industrial (INPI) para concessão de patentes. Conclusão: Fluxos de questionamento burocrático no interior do Executivo ou entre o Executivo e demais poderes envolvendo a AGU são expressões importantes da judicialização no país, podendo gerar orientações e normatizações com alto impacto sobre o sistema de saúde brasileiro, que merecem maiores estudos.

Palavras-chave: Direito Sanitário; política de saúde; Sistema Único de Saúde; administração pública/legislação e jurisprudência.

Key-words: Health Law; health policy; Public Administration/legislation and jurisprudence. 
Ran Hirschl (2006) define a judicialização das políticas como o crescimento do recurso ao Judiciário para questões relacionadas a impasses morais, aspectos das políticas públicas e controvérsias da política.

Distingue três grandes categorias de judicialização: (a) a impregnação da esfera política e fóruns de elaboração de políticas pelo discurso e jargão jurídicos; (b) a judicialização da implementação de politicas públicas mediante revisões administrativas ou judiciais e (c) a judicialização da "política pura", onde se transferem para o âmbito jurídico questões de natureza e significância claramente políticas, inclusive relacionadas à legitimidade do regime político, sendo o exemplo brasileiro mais recente o julgamento do mensalão pelo Superior Tribunal Federal.

$\mathrm{Na}$ saúde, a perspectiva mais comum da pesquisa sobre judicialização no Brasil é a das revisões judiciais da implementação das políticas, onde são transferidos para tribunais decisões sobre a implementação de políticas públicas configuradas pelas Leis Orgânica da Saúde - Lei 8080. Na maioria dos casos, o que está em pauta é a garantia do direito à saúde individual ou de grupos em face às dificuldades de implementação de políticas, como as de assistência farmacêutica pelo Sistema Único de Saúde (SUS), ou a negativa de acesso a serviços pelos planos privados de saúde (Machado et al., 2011; Ventura et al.,2010).

Esse fenômeno está vinculado à existência de uma Constituição que explicita direitos e valores a serem resguardados pelo Estado, e que passam ser invocados por indivíduos e grupos sociais que se sintam lesados, com judicialização dos conflitos sociais e políticos. Juízes são chamados crescentemente a interpretar normas constitucionais ou infraconstitucionais e, por vezes, a decidir e a agir de um modo semelhante ao legislador (Verbicaro, 2008).

Mas a judicialização não se restringe ao papel direto do Judiciário na implementação de políticas. Grupos com atuação politica ou administrativa passam a ter que considerar a possibilidade de ação legal e a proteger suas propostas de forma a garantir que elas sejam apresentadas de forma juridicamente embasada, em antecipação a essas ações. Na Administração Pública brasileira, isso redundou na multiplicação de Procuradorias, Assessorias Jurídicas em órgãos de todas as esferas federativas e no fenômeno vislumbrado por Alexis de Tocqueville para a política americana: a transformação de questões politicas em questões legais, com 
considerações e retórica de ordem legal ou constitucional adquirindo importância central em decisões de cunho abertamente político. (Ferejohn, 2002)

Nesse sentido, destaca-se o papel da Advocacia Geral da União (AGU). Antes da CF 88, os membros da AGU desenvolviam cumulativamente as funções hoje outorgadas ao Ministério Público e a de procuradores da República. Nos termos do artigo 127 da CF 88, porém, o Ministério Público ficou definido como instituição permanente incumbida da defesa da ordem jurídica, do regime democrático, dos interesses individuais indisponíveis (ditos imanentes à personalidade humana e próprios de uma coletividade) e dos direitos coletivos e difusos (caracterizados por abranger não indivíduos ou grupos singulares, mas aqueles que possuem necessariamente algo em comum). Integra, assim, sua competência principal zelar pelos serviços de relevância pública e pela promoção dos direitos constitucionais, sendo que, dentre estes, está o direito à saúde (entendido como direito individual, coletivo e difuso, conforme o artigo 197 da Constituição) (Machado, 2008).

Por outro lado, nos termos do art. 131 da CF 88, a Advocacia-Geral da União passou a ater-se a prestar consultoria e assessoramento jurídicos aos órgãos do Poder Executivo, e exercer a representação judicial e extrajudicial da União (Poderes Executivo, Legislativo e Judiciário, e órgãos públicos que exercem Função Essencial à Justiça)- portanto atuação simultaneamente no contencioso e consultiva (Silva, 2010).

O Ministério Público (MP) tem recebido grande destaque como protagonista da defesa do Direito à Saúde. Nos aspectos mais tradicionalmente pesquisados da judicialização das políticas de saúde, a AGU atua no contencioso como procuradora da União em processos em que os autores buscam garantir o acesso a bens e serviços de saúde acionando a União. A AGU contabilizou essas demandas em 12.436 processos na Justiça em 2011, em causas da ordem de quase $R \$ 250$ milhões. Em muitas delas, o MP atuava em prol dos autores.

Em acréscimo às atribuições tradicionais relacionadas à atuação contenciosa, ganhou também força a atuação consultiva da Advocacia Geral da União sobre questões com impacto potencialmente elevado para as politicas de saúde. Pareceres aprovados pelo Presidente da República e publicadas em Diário Oficial (DO) tem poder vinculante para toda a administração federal. 


\section{Método}

Trata-se de estudo exploratório, no qual foram revistos os pareceres, as normas, as resoluções e as informações constantes do site da AGU referentes ao período de 1993 a maio de 2013.

Esses documentos foram selecionados e categorizados segundo aqueles relacionados à saúde e com caráter consultivo. Destes, foram selecionados e analisados três com significativo impacto potencial nas políticas e na configuração do sistema de saúde brasileiro.

Os seguintes aspectos foram estudados: a origem da solicitação do parecer (demandante ou situação que justificou), a argumentação que sustentou as conclusões finais (tese mestra) e sua base de sustentação na constituição, na jurisprudência ou em disciplina externa ao direito, bem como se adquiriu caráter normativo ou não (publicado juntamente em DO com o despacho presidencial adquire caráter normativo).

\section{Resultado}

Os três documentos analisados em profundidade foram:

- o Parecer no GM-016, de 29 de dezembro de 2000, originado na Casa Civil, que interpreta a EC-29 na perspectiva da contribuição federal para o financiamento do SUS;

- a Informação 002/2008/PROGE/GECOS, um estudo sobre a participação de capital estrangeiro em operadora de plano de saúde com rede própria de serviços de assistência à saúde e exegese do $\S 3^{\circ}$ do art. 199 da Constituição Federal, que criou as bases para a aprovação pela ANS da aquisição da AMIL pela empresa Unitedhealthcare; e

- o Parecer no 337/PGF/ 2010, que preserva a competência da Agência Nacional de Vigilância Sanitária (ANVISA) e do Instituto de Nacional de Propriedade Industrial (INPI) para concessão de patentes de um medicamento, definindo que cabe ao INPI analisar o cumprimento dos requisitos para a concessão de uma patente previstos na legislação e à Anvisa avaliar a segurança e eficácia do medicamento. 


\section{Parecer no GM-016, de 29 de dezembro de 2000}

A primeira situação selecionada em que a AGU foi provocada a emitir parecer sobre uma questão de alto impacto potencial para a configuração do sistema de saúde brasileiro versa sobre a responsabilidade federativa no financiamento da saúde e ocorreu quando do inicio da vigência Emenda Constitucional 29. A Emenda Constitucional 29 estabelece que: "nos exercício financeiros posteriores ao exercício de 2000, do ano de 2001 ao ano de 2004, a União aplicará, a título de piso, ou seja, no mínimo, nada impedindo, obviamente, que aplique mais, de acordo com as necessidades e a disponibilidade do Tesouro, o equivalente ao valor apurado no ano anterior, vale dizer, o valor apurado no ano 2000, isto é, o montante empenhado nessas ações e nesses serviços públicos no exercício financeiro de 1999, acrescido de, no mínimo, cinco por cento, corrigido, ainda, sucessiva e cumulativamente pela variação nominal do Produto Interno Bruto - PIB."

De forma resumida, o objeto da Consulta feita pela Casa Civil da Presidência da República foi a interpretação do art. $7^{\circ}$ da Emenda Constitucional no 29 que versava sobre esse período de transição. Havia discordâncias entre o entendimento da expressão "valor apurado" entre os Ministérios da Fazenda e da Saúde.

O primeiro entendia que a expressão "valor apurado" no ano anterior significava o valor calculado para o ano 2000, adicionando-se a esse valor encontrado, a variação do PIB para os anos subsequentes. Já o Ministério da Saúde concebia a expressão como valor apurado no ano anterior, referindo-se não a um ano fixo, mas a cada um dos anos anteriores. Segundo essa regra, os valores iriam elevando-se gradualmente.

A Advocacia-Geral da União inicialmente acompanhou o parecer do Ministério da Fazenda e elaborou o Parecer GM-016. Segundo a Câmara dos Deputados, o objetivo foi provar "por meio de uma intrincada, confusa e, sobretudo, equivocada interpretação" (Câmara dos Deputados, 2003), que os valores dos exercícios de transição não teriam qualquer variação, porque seriam todos calculados com base no exercício de 2000.

Inicialmente, o Presidente da República aprovou em 4/1/2001 o parecer, publicado no DO de 10/1/2001. Diante da grande pressão política gerada pela medida, acolhendo proposta do Advogado-Geral da União, exarou despacho, publicado no DO de 18/12/2001, tornando sem efeito a publicação do. Este parecer, 
então desprovido que foi da força normativa que lhe emprestava o art. 40 da LC 73/1993, deixou de vincular os órgãos e as entidades que compõem a Administração Pública Federal no tocante à interpretação a ser dada ao art. $77,1, b$, do ADCT, incluído pela Emenda Constitucional 29, de 13/9/2000.

O parecer foi também objeto do Projeto de Decreto Legislativo n 498, de 2003 , do Deputado Alceu Collares, que pretendia sustar os efeitos do parecer GM-016, da Advocacia-Geral da União, para restabelecer os recursos federais aplicados na área da Saúde, em decorrência da Emenda Constitucional nº 29/2000.

Este quadro configura um impasse da judicialização intragovernmental, uma vez que pareceres de órgão da União que possuíam caráter normativo foram tornados sem efeito por ato da Presidência e contestado por projeto de decreto que vem a sustar efeitos no legislativo, multiplicando assim os efeitos da judicialização na ação governamental.

\section{Informação 002/2008/PROGE/GECOS}

Nos últimos anos, passou a ser especialmente ativa a atuação da AGU na Agência Nacional de Saúde Suplementar (ANS), que dispõe de uma procuradoria específica. Além de atuar intensamente nas questões relacionadas a ressarcimento ao SUS pelos planos de saúde, também pode ser solicitada a elaborar estudos e pareceres de interesse da Agência. O segundo documento analisado neste trabalho é a Informação 002/2008/PROGE/GECOS, elaborada por essa Procuradoria, que estuda a "possibilidade de participação de capital de capital estrangeiro em operadora com rede própria de serviços de saúde e exegese do §3ํำ do artigo 199 da CF”.

O estudo foi solicitado à AGU em 2007 por ocasião da oferta pública inicial (IPO) internacional de ações da operadora de saúde AMIL. Na prática, essa IPO levaria uma grande parcela de usas ações da empresa às mãos de investidores internacionais. Tendo em vista a existência de uma rede de serviços própria da AMIL, isso equivaleria à presença de capital estrangeiro na operação de hospitais nacionais.

O estudo considera que apenas a uma leitura superficial pode-se interpretar o texto constitucional como uma vedação à participação de capital estrangeiro na saúde. Inicialmente invoca a permissão excepcional à participação de capital estrangeiro prevista na Constituição para, citando Manoel Gonçalves Ferreira Filho e Jose Afonso da Silva, sugerir que "diante do conflito entre a vedação e a permissão 
excepcional sem critérios bem-definidos", possa surgir o entendimento "pela ausência de efetividade da vedação".

No desenvolvimento do estudo, passa a ser apoiada a tese de que "embora não haja um direito constitucional à liberdade de iniciativa quando esta tenha origem estrangeira, tanto a permissão quanto a vedação à entrada do capital estrangeiro devem ser feitas com base no interesse nacional".

Segue para asseverar que, em duas situações estaria justificada a participação de capital estrangeiro. Na área pública, quando não houver recursos para garantir acesso à tecnologia de ponta, seguindo parecer do jurista Ives Gandra da Silva Martins elaborado a pedido da Frente Parlamentar de Saúde. Nessa vertente, serviria como garantia a integralidade. No universo da saúde suplementar (art.198, II, CF) a exceção seria permitida em nome da livre concorrência (art 170, IV, CF). De acordo com o estudo: "Se o legislador ordinário considera que a participação de capital estrangeiro em operadoras brasileiras de plano de saúde reforça a concorrência, aprimorando a tecnologia e reduzindo custos, em prol do consumidor, encontra-se autorizado pelo legislador constituinte originário". Conclui que, em nome da livre concorrência, o legislador ordinário pode permitir a participação de capital estrangeiro em pessoas jurídicas que prestam assistência a saúde e não apenas operem planos.

Embora sem nenhum poder vinculante, visto tratar-se de uma simples "Informação", essa peça produzida pela AGU foi utilizada pela Agência Nacional de Saúde Suplementar (ANS) para fundamentar a aprovação do maior negócio já realizado no setor de saúde no Brasil - a compra, por 10 bilhões de reais, da AMIL, maior operadora de planos de saúde brasileira, pelo grupo norte-americano United Health Group, em 8 de outubro de 2012, e que envolveu 22 hospitais da rede própria da Amil. Embora o princípio invocado no estudo seja o da livre concorrência, a operação não foi analisada pelo órgão responsável pela garantia da observância de regras de concorrência, o Conselho Administrativo de Defesa Econômica (CADE), e foi aprovada em tempo recorde, 13 dias, pela ANS. (Agostini \& Matais, 2012)

Segundo Edson de Godoy Bueno, que permanece diretor presidente do conselho de administração da Amilpar: "Nossa união com a United Health Group nos permitirá trazer avançadas tecnologias de inovação, iniciativas de serviços e programas clínicos para reforçar ainda mais a saúde no Brasil, o que permitirá que a Amil cresça ainda mais rápido e faça mais para cuidar de nossos pacientes e servir 
nossos clientes como uma empresa líder no mercado brasileiro." Ou seja, reforça-se um argumento da peça produzida pela AGU, que sustenta a entrada de capital estrangeiro na saúde. (Agostini \& Matais, 2012)

Concomitantemente, tramita no legislativo um Projeto Lei 4542/12 que permitirá a participação minoritária de estrangeiros (pessoas físicas e jurídicas) em assistência à saúde.

\section{Parecer no 337/PGF/ 2010}

O Parecer nํ 337/PGF/ 2010 integra uma sucessão de pareceres e resoluções no âmbito do Poder Executivo que tratam da definição dos procedimentos para registro de propriedade industrial de produtos de saúde, onde a maioria dos produtos são medicamentos.

O primeiro Parecer sobre o tema, no 201/PGF/2009, foi motivado por encaminhamento para a Adjuntoria de Contencioso da Procuradoria Geral, solicitando orientação sobre processo judicial em que eram discutidos atos praticados pelo Instituto de Propriedade industrial (INPI) e pela Anvisa referente a necessidade de aprovação prévia por esta última dos procedimentos de patente de medicamentos.

Esse parecer interpretou a Lei de Propriedade Industrial (art. 51 da Lei no 9.279, de 1996) e contestou a Resolução Colegiada da Anvisa de $n^{\circ}$ 45, de 23 de junho de 2008, a qual previu a prévia anuência da Anvisa para a concessão de patentes para produtos e processos farmacêuticos (Art. 4. "Após recebimento dos pedidos de patente encaminhados pelo INPI, a Anvisa realizará a sua análise quanto à influência aferindo cumprimento de requisitos de patenteabilidade e demais critérios estabelecidos pela legislação vigente mediante decisão consubstanciada em parecer técnico emitido pela unidade organizacional competente no âmbito da Agência")

Neste último parecer, afirmou-se que as atribuições do INPI e da Anvisa seriam diferentes, específicas. A Procuradoria concluiu que não seria atribuição da Anvisa executar anuência prévia ou análise fundada nos critérios de patenteabilidade (novidade, atividade inventiva e aplicação industrial), porque essa seria uma atribuição própria e única do INPI, conforme estabelecido na Lei 5.648/70. Afirmou-se que a Anvisa deveria atuar nos limites de sua competência, focada na segurança, isto 
é, evitar a produção e a comercialização de produtos e serviços potencialmente nocivos à saúde humana.

O Parecer no 337/PGF/ 2010 reitera esse mesmo entendimento. Posteriormente, pela Portaria Interministerial MS/MDIC/AGU 1065/12, ficou estabelecido um fluxo de procedimentos mais eficiente entre a Anvisa e o INPI e tornou-se necessária a atualização da Resolução RDC 45/2008. O novo fluxo determinava que os pedidos de patentes de produtos ou processos farmacêuticos apresentados ao INPI seriam encaminhados diretamente à Anvisa e que, somente após a sua manifestação, o INPI daria início ao exame do pedido. Uma nova RDC, a RDC 21/2013 publicada em DO em 15 de abril de 2013, une o foco da saúde publica e a proteção aos direitos de propriedade industrial. As novas regras para anuência prévia estabelecem que a Anvisa dará prioridade a processos e produtos farmacêuticos que sejam de interesse do SUS, podendo opinar em relação a patentabilidade de produtos considerados estratégicos para o mesmo. Cria-se assim um meio termo entre a posição original da Anvisa e a da AGU.

\section{Discussão}

Recentes trabalhos defenderam uma estratégia do tipo "judicialização de cima para baixo", que enfatizam o apoio da esfera política como precondição necessária para a judicialização de políticas ditas "puras" (Hirschl, 2008). Observa-se que atividades jurídicas - que criam fluxos de questionamento burocrático dentro do Executivo ou entre o Executivo e os demais poderes - também são expressões importantes da judicialização no país.

Ganha maior importância para 0 contexto brasileiro a análise desses pareceres, que denotaram que a posição da AGU em relação a esses temas muitas vezes apresenta imbricações com interesses econômicos e fiscais, em detrimento da consideração de potenciais tensões entre estas decisões e interesses sociais mais amplos.

Ainda que não tenham força vinculante, poderíamos apelidá-la de uma atuação de "executivização" das políticas na defesa de posições do governo federal, não necesariamente identificadas com a defesa de interesses individuais indisponíveis e dos direitos coletivos e difusos. 


\section{Conclusão}

Impactos da judicialização da politica pública comum via revisões administrativas, pareceres e outras peças de cunho jurídico emitidos por setores especializados podem ter implicações amplas e imediatas na configuração do sistema de saúde. Os estudos no campo da judicialização demandam uma atenção maior a atos administrativos da AGU, na perspectiva de seus impactos potenciais sobre distintas dimensões da política de saúde.

\section{Referências:}

AGOSTINI, Renata \& MATAIS, Andreza. Maior negócio do setor de saúde, compra da Amil foi aprovada em 13 dias pela ANS. Folha de São Paulo 25/11/2012 - Caderno Cotidiano. C1

BRASIL. Câmara dos deputados. Projeto de Decreto Legislativo $n^{\circ} 498$, de 2003. (Do Sr. Alceu Collares). Susta os efeitos do parecer GM-016, da Advocacia-Geral da União, para restabelecer os recursos federais aplicados na área da Saúde, em decorrência da Emenda Constitucional nำ29/2000.

FEREJOHN, John. Judicializing politics, politicizing law. Law and Contemporary Problems; 65(3):41-68, 2002.

HIRSCHL, Ran. The Judicialization of Mega-Politics and the Rise of Political Courts. Annu. Rev. Polit. Sci.; 11:93-118, 2008.

HIRSCHL, Ran.The New Constitutionalism and the Judicialization of Pure Politics Worldwide. Fordham Law Review; 75:721-753, 2006.

MACHADO, Felipe Rangel de Souza. Contribuições ao debate da judicialização da saúde no Brasil. Rev Direito Sanitário; 9(2):73-91; 2008.

MACHADO, Marina Amaral de Ávila et al. Judicialization of access to medicines in Minas Gerais state, Southeastern Brazil. Rev. Saúde Pública; 45(3):590-598, 2011.

SILVA, Jose Afonso. Curso de Direito Constitucional Positivo. 34 ed. São Paulo : Malheiros Editores, 2010.

VENTURA, Miriam; SIMAS, Luciana; PEPE, Vera Lúcia Edais e SCHRAMM, Fermin Roland. Judicialização da saúde, acesso à justiça e a efetividade do direito à saúde. Physis; 20(1): 77-100, 2010.

VERBICARO, Loiane Prado. Um estudo sobre as condições facilitadoras da judicialização da política no Brasil. Rev. Direito GV; 4(2):389-405, 2008. 